\title{
CONCENTRAÇÃO DE MERCADO E DESEMPENHO DAS INDÚSTRIAS BRASILEIRAS DE PAPEL E CELULOSE - RECORRENDO À MODELAGEM DE FLEURIET PARA ANALISAR O PARADIGMA ECD
}

\section{MARKET CONCENTRATION AND PERFORMANCE OF BRAZILIAN PULP AND PAPER INDUSTRIES - BASED ON FLEURIET MODELING TO ANALYZE THE SCP PARADIGM}

FLAVIANO COSTA

Mestrando em Contabilidade Pela Universidade Federal do Paraná

Especialista em Contabilidade e Finanças pela Universidade Federal do Paraná Curitiba/PR, Brasil

E-mail: flaviano_costa@hotmail.com
PAULO MELLO GARCIAS

Doutor em Economia pela Universidade de São Paulo Professor Adjunto do Departamento de Ciências Econômicas da Universidade Federal do Paraná

Curitiba/PR, Brasil

E-mail: paulomg@ufpr.br

\section{Resumo}

O presente estudo objetivou analisar se existe uma relação entre o desempenho das indústrias de papel e celulose, por meio da utilização da modelagem de Fleuriet e os níveis de concentração de mercado, entre os anos de 2003 e 2007. Metodologicamente, o presente artigo pode ser categorizado como: [1] estudo formal; [2] ex post facto; [3] descritivo e causal e; [4] longitudinal porque é feito em um período de cinco anos. A fonte de dados utilizada para identificação e classificação das indústrias de papel e celulose brasileiras foi o banco de dados da BRACELPA - Associação Brasileira de Celulose e Papel. Optou-se pela utilização do CRk e do índice de Hirschman-Herfindahl $(\mathrm{HH})$ para mensurar a concentração de mercado da celulose e papel. Verificou-se que o saldo em tesouraria (T), o capital de giro $(C C L)$ e a necessidade de capital de giro (IOG), que definem o desempenho financeiro e operacional das organizações, na metodologia de Fleuriet, mantiveram-se em patamares aceitáveis e muito sólidos para as quatro maiores empresas do setor, com exceção dos primeiros anos analisados, enquanto a concentração manteve uma ligeira tendência de queda.Os resultados indicam que a relação entre concentração e desempenho depende de série de tempo e dos indicadores utilizados.

Palavras-chave: concentração de mercado; desempenho; paradigma Estrutura-CondutaDesempenho; Modelagem de Fleuriet.

\begin{abstract}
This study aimed to analyze whether there is a relationship between the performance of pulp and paper industries, through the use of Fleuriet modeling and the concentration levels of the market, between the years 2003 and 2007. Methodologically, this paper can be categorized as: [1] formal study, [2] ex post facto, [3] descriptive and causal and, [4] longitudinal, because it is done over a period of five years. The data source used for identification and classification of Brazilian pulp and paper industries was the database of BRACELPA Associação Brasileira de Celulose e Papel. It was decided to use the CRk and HirschmanHerfindahl Index $(\mathrm{HH})$ to measure the concentration of pulp and paper market. It was found that the balance in cash (T), the working capital (CCL) and the need for working capital (IOG), which define the operational and financial performance of organizations, the Fleuriet methodology, remained at levels acceptable and very robust for the four largest companies in the industry, except for the first years analyzed, while the concentration remained a slight downward trend. The results indicate that the relationship between concentration and performance depends on the time series and indicators used.
\end{abstract}

Key words: market concentration, performance, Structure-Condut-Performance paradigm, Fleuriet Modeling. 


\section{INTRODUÇÃO}

No contexto social contemporâneo, em razão das mutações que vêm acontecendo, decorrentes do rápido desenvolvimento econômico nas últimas décadas, da globalização que traz consigo a queda das barreiras geográficas, da elevação mundial do nível de educação; da evolução tecnológica, da velocidade na produção e transmissão das informações e, todas as demais mudanças que atualmente se observa (FREITAS, 2000), os estudos referentes à Economia Industrial apresentam-se crescentes. Corroborando com essa ideia, Leite (1998), expõe que este dinamismo é resultado das atitudes dos compradores e vendedores, que são responsáveis pelos ciclos de produção, circulação e consumo de produtos e serviços.

A década de 90 caracterizou-se por uma profunda mudança de caráter econômico no Brasil, especialmente no complexo industrial brasileiro, resultante, entre outros fatores, da abertura de mercados que contribuiu para o processo de globalização. Devido a essa exigência competitiva para concorrer com as demais empresas de seu setor, as corporações industriais verificaram a importância de mudanças estruturais, tais como: modernização do parque fabril, especialização da produção e redução de custos, visando obter vantagens competitivas e fatores de sucesso para os agentes envolvidos na cadeia produtiva (MACHADO et al, 2008).

Devido a essas mudanças ocorridas no ambiente econômico dos últimos anos, optouse por estudar, na presente investigação, o setor industrial de papel e celulose, sob a perspectiva do Paradigma Estrutura-Conduta-Desempenho. Essa escolha justifica-se pela importância do estudo do processo de concentração industrial, uma vez que comprova o poder de mercado das maiores empresas do setor e sua relação com o desempenho das organizações estudadas e também pelo número de pesquisas efetuadas sobre o assunto (ADAMI e MORAES, 2005; MONTEBELLO, 2006; SIMÕES, 2006; MACHADO et al., 2008). De acordo com Leite (1998), o modelo teórico proposto no Paradigma Estrutura-CondutaDesempenho, pressupõe que há influência da estrutura sobre a conduta e desta última variável sobre desempenho, porém, é possível eliminar o componente intermediário e analisar diretamente o efeito da estrutura sobre o desempenho.

A opção pelo setor de papel e celulose deve-se: [1] à sua relevância na cadeia produtiva brasileira, levando-se em consideração o total de produção; [2] à interdependência destes dois produtos (papel e celulose), pois, a celulose é a matériaprima para a produção do papel, que provoca uma rivalidade mercadológica entre clientes e fornecedores; [3] ao considerável aumento da produção e do consumo de papel nos últimos anos (BRACELPA, 2008) o que conduz à elevação da competitividade.

Com base nas alegações mencionadas, a questão orientadora do presente estudo é a seguinte: existe relação entre o desempenho das indústrias brasileiras de papel e celulose $e$ os níveis de concentração de mercado (estrutura de mercado) do setor no período compreendido entre os anos de 2003 e 2007? O objetivo subjacente nesse enunciado é analisar se existe uma relação entre o desempenho das indústrias de papel e celulose, por meio da utilização da modelagem de Fleuriet e os níveis de concentração de mercado, entre os anos de 2003 e 2007. A proposta é desenvolver essa análise sob a perspectiva do Paradigma Estrutura-Conduta-Desempenho (ECD), preconizado por Mason (1939) e Bain (1959), eliminando-se o termo intermediário (conduta) e focando tão somente nas variáveis: estrutura e desempenho.

0 presente artigo está estruturado em mais sete seções. Nas próximas quatro seções apresenta-se o referencial teórico, partindo de uma contextualização do setor de papel e celulose brasileiro. Referencia-se o Paradigma Estrutura-Conduta-Desempenho e desenvolve-se uma revisão sobre os indicadores de concentração de mercado e a 
Modelagem de Fleuriet. Na sexta seção, são definidos os procedimentos metodológicos utilizados na investigação. Na sétima seção são discutidos e analisados os resultados obtidos por meio do ferramental utilizado na pesquisa. Por fim, na última seção, são expostas as considerações finais, as limitações da presente investigação e ainda sugestões para pesquisas futuras.

\section{SETOR DE PAPEL E CELULOSE NO BRASIL}

A indústria papeleira no Brasil se desenvolveu de modo gradativo em etapas sucessivas de substituição de importações e integração produtiva, iniciando-se no século passado, para suprir a demanda das empresas gráficas. Por outro lado, a produção de celulose, é mais recente e a primeira empresa desse segmento data da década de 1950 (JORGE, 1993; SOARES, 1993).

Desde o processo de abertura dos mercados em 1990, o Brasil tem mantido uma tendência de crescimento das exportações de papel e celulose, proporcionando crescimento do saldo comercial do setor, dado pela diferença entre as exportações e as importações. Essa tendência torna-se mais acentuada nesta última década. A Figura 1 ilustra a evolução histórica do saldo da balança comercial do Setor de Papel e Celulose brasileiro. As exportações de celulose concentraram-se na Europa $(53,3 \%)$ enquanto as referentes a papel tiveram uma maior concentração na América Latina $(57,8 \%)$.

Referindo-se ao setor de papel e celulose, o BNDES (2009, p.11), afirma que, “[...] a capacidade de criar produtos diferenciados, aliada a relações comerciais estáveis baseadas em qualidade e assistência técnica são hoje a chave para o sucesso na competição deste setor [...]". Complementarmente, tal instituição desvela que, a principal vantagem competitiva do Brasil é a sua tecnologia florestal.

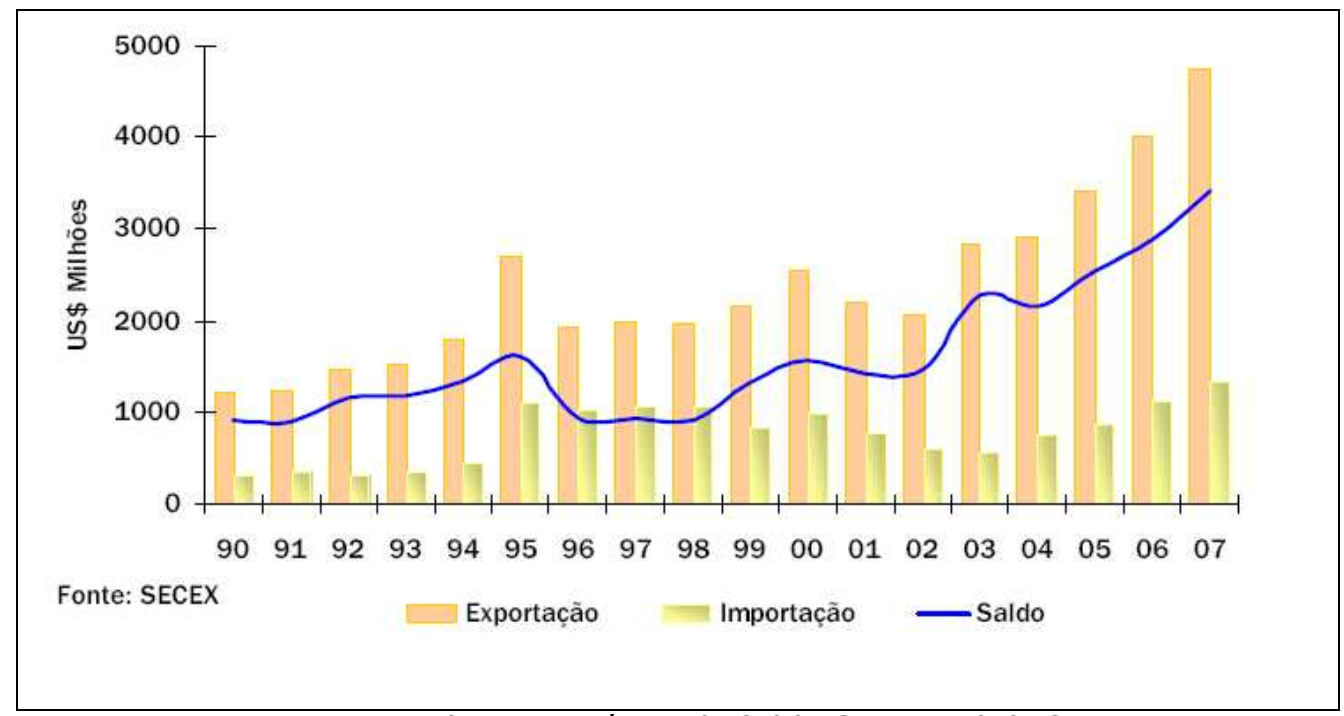

Figura 1 - Evolução Histórica do Saldo Comercial do Setor Fonte: Associação Brasileira de Celulose e Papel - BRACELPA

No cenário econômico contemporâneo o Brasil é um dos líderes na produção de papel e celulose no mundo. As estatísticas do ano de 2007 demonstram que o país definitivamente conquistou reconhecimento como um dos maiores players mundiais ao ultrapassar o Japão em produção de celulose, aproximando-se da Finlândia e Suécia, grandes produtores 
europeus. A Tabela 1 reúne os grandes produtores mundiais de papel e celulose com a classificação brasileira.

Tabela 1 - Maiores Produtores Mundiais de Celulose e Papel (2007)

\begin{tabular}{|c|c|c|c|}
\hline \multicolumn{2}{|c|}{ Celulose } & \multicolumn{2}{c|}{ Papel } \\
\hline País & $\mathbf{1 0 0 0} \mathbf{t}$ & País & $\mathbf{1 0 0 0} \mathbf{~ t}$ \\
\hline 1. EUA & 53.215 & 1. EUA & 84.073 \\
\hline 2. Canadá & 23.677 & 2. China & 65.000 \\
\hline 3. China & 18.160 & 3. Japão & 31.106 \\
\hline 4. Finlândia & 13.066 & 4. Alemanha & 22.655 \\
\hline 5. Suécia & 12.240 & 5. Canadá & 18.170 \\
\hline 6. Brasil & $\mathbf{1 1 . 9 9 8}$ & 6. Finlândia & 14.151 \\
\hline 7. Japão & 10.884 & 7. Suécia & 12.066 \\
\hline 8. Rússia & 7.370 & 8. Coreia do Sul & 10.703 \\
\hline 9. Indonésia & 5.672 & 9. Itália & 10.009 \\
\hline 10. Chile & 3.550 & 10. França & 10.006 \\
\hline 11. Índia & 3.250 & 11. Brasil & $\mathbf{9 . 0 0 8}$ \\
\hline & & 12.Indonésia & 8.862 \\
\hline TOTAL MUNDO & $\mathbf{1 9 2 . 1 7 7}$ & & $\mathbf{3 8 1 . 5 5 1}$ \\
\hline
\end{tabular}

Fonte: Associação Brasileira de Celulose e Papel - BRACELPA

Conforme estudos do BNDES (2009, p. 14), o Brasil por sua "[...] localização geográfica, dimensão territorial e capacitação técnica e mercadológica [...]" é um país atrativo para o desenvolvimento de indústrias de papel, celulose ou qualquer outro produto florestal. Porém, o que afasta potenciais investidores e enfraquece o investimento de capital nesse setor é a instabilidade econômica.

\section{PARADIGMA ESTRUTURA-CONDUTA-DESEMPENHO (ECD)}

A Economia Industrial (origem francesa) ou Organização Industrial (origem inglesa) se desenvolveu a partir da década de 1950 com o intuito de melhor estudar as relações entre empresas, mercados, instituições e processos. No Brasil, a Economia Industrial é um ramo de conhecimento relativamente novo da Economia que visa demonstrar uma nova metodologia de investigação do funcionamento dos diversos setores industriais e toda a dinâmica que os respalda (KUPFER e HASENCLEVER, 2002; KON, 1999).

Diante dessa perspectiva pode-se depreender que no Brasil há um crescente interesse por temas voltados a custos, inovação, preços, crescimento das empresas e competitividade, estrutura de mercado e concentração, dentre outros temas voltados a essa ramificação da ciência econômica. Pode-se visualizar essa assertiva pela quantidade de estudos que têm sido desenvolvidos à luz dessas problemáticas (JORGE, 1993; SOARES, 1993; LEITE, 1998; MONTEBELLO, 2006; ROCHA, BUENO e PIRES, 2007; MACHADO et al, 2008). Nesse sentido, com a finalidade de ampliar o número de publicações que tragam visões diferenciadas para essas temáticas, a presente investigação adota essa linha de pesquisa como um caminho para explicar o desempenho das organizações.

0 paradigma de Estrutura-Conduta-Desempenho (ECD) pressupõe que o desempenho das indústrias depende da conduta de vendedores e compradores, que é dependente da estrutura do mercado. A estrutura, por sua vez, está sujeita a condições básicas como a tecnologia e a demanda dos produtos (CARLTON e PERLOFF, 1994). Nesse contexto, partese do pressuposto que "[...] maior concentração de oferta (estrutura) implica em maior 
probabilidade de colusão (conduta) e, por consequência, de preços e lucros mais elevados [...]” (KUPFER e HASENCLEVER, 2002, p. 497).

De acordo com Scherer e Ross (1990) o modelo da estrutura-conduta-desempenho, procura identificar um conjunto de variáveis que influenciam o desempenho econômico das organizações e determinar relações entre essas variáveis e o resultado final. Confirmando essa ideia, Cabral (2000) afirma que o modelo ECD propõe uma relação de causalidade entre estrutura, conduta e desempenho. A Figura 2 ilustra e planifica, de modo que se tenha uma melhor visualização do fluxo e das inter-relações do Paradigma em questão.

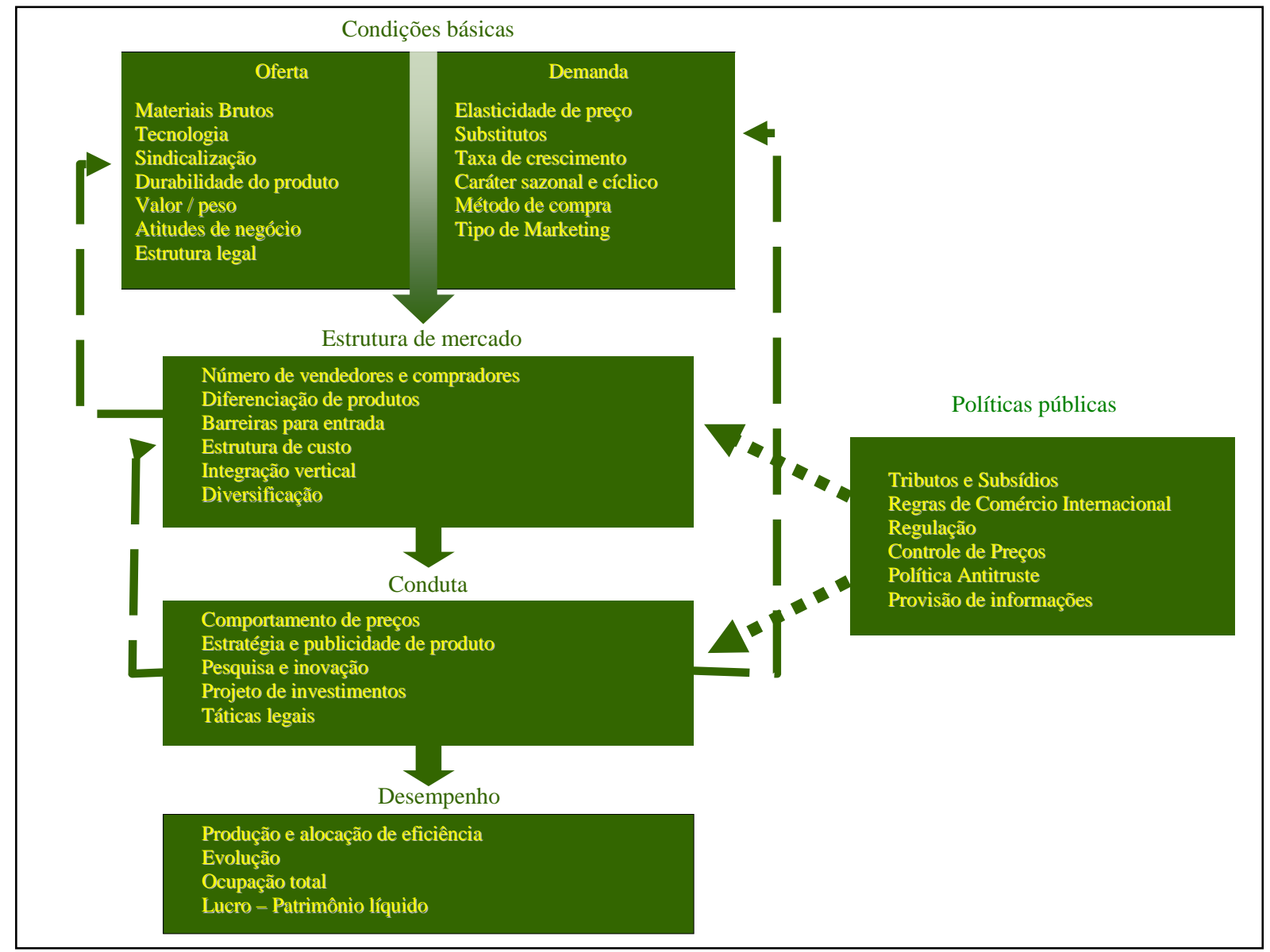

Figura 2 - Paradigma Estrutura-Conduta-Desempenho

Fonte: Scherer e Ross (1990, p.6)

Por meio da Figura 2 é possível perceber que estão contidos na variável desempenho, a qualidade do produto, a evolução técnica pela qual o produto atinge essa qualidade, a eficiência produtiva e alocativa e os lucros. Na conduta estão contidos os atributos de comportamento de preços, estratégia e publicidade dos produtos, pesquisa e inovação, projetos de investimentos e táticas legais. Como já se mencionou anteriormente essa conduta é influenciada pela estrutura de mercado, ao qual estão vinculadas as variáveis de número de vendedores e compradores, diferenciação de produtos, barreiras para entrada, estrutura de custos, integração vertical e diversificação. Entretanto, vê-se que todas essas variáveis que definem a ECD são influenciadas pelas condições básicas de oferta, demanda e políticas públicas.

Contudo, contrapondo-se a essa visão, Donsimoni, Geroski e Jacquemin (1984) desenvolveram uma nova vertente de pesquisas que defende a endogeneidade de parte das variáveis de estrutura. Essa nova teoria, também denominada "não causal" afirma que o 
nível de concentração industrial não é uma determinante exógena da conduta, mas que é útil para avaliar o desempenho industrial, apesar de sua endogeneidade. Corroborando com essa idéia, Schmalensee (1989) assevera que empiricamente existem dois aspectos que afrontam a linearidade do Paradigma Estrutura-Conduta-Desempenho: [1] incapacidade das condições básicas explicarem a concentração de maneira unidirecional, ainda que correlacionadas e; [2] fraco desempenho da concentração como elemento explicativo de variáveis de desempenho.

Seguindo esta mesma linha argumentativa, Rocha, Bueno e Pires $(2004$, p. 3) evidenciam que "[...] assim como nas extensões do modelo ECD, a concentração aparece como um resultado de um processo de crescimento e não como um determinante [...]". Portanto, pode-se depreender que a relação de causalidade no Paradigma EstruturaConduta-Desempenho é questionável, uma vez que as variáveis estrutura e desempenho podem ser causadas por condicionantes externas e não necessariamente estão correlacionadas.

Kupfer e Hasenclever (2002) ressaltam também que dentre as lacunas do Paradigma ECD, a questão da endogeneidade das variáveis foi a mais relevante, pois fez surgir uma nova linha de pesquisa nas teorias sobre organização industrial, fundamentada na escola marginalista. Introduziu-se a Teoria dos Jogos que partia do princípio de que as condições básicas e as condutas são variáveis exógenas e a estrutura e o desempenho são as variáveis endógenas.

Outro fator relevante é que ao existir a causalidade entre as variáveis, é possível que esse efeito ocorra com uma determinada defasagem temporal (KUPFER e HASENCLEVER, 2002). Um exemplo disso é a empresa que elabora um novo produto com sua tecnologia. No início, ela terá um desempenho elevado e será a única do mercado, mas, com o passar do tempo, essa tecnologia será imitada por outras empresas que farão com que a concorrência aumente e conseqüentemente a concentração de mercado se pulverize, fazendo com que os índices de desempenho mantenham-se em patamares condizentes com a ocupação de mercado.

No presente artigo, eliminou-se a conduta para análise tão-somente da relação existente entre a estrutura e o desempenho. Nesse contexto, Carlton e Perloff (1994), esclarecem que se têm dois estágios no estudo da ECD: [1] uma medida de desempenho obtida diretamente e não por estimativa e; [2] medidas de estrutura são usadas para explicar a diferença no desempenho do mercado por meio das indústrias. Destarte, optouse em medir estrutura de mercado de papel e celulose por meio do indicador de concentração de mercado CRk e do índice de Hirschman-Herfindahl $(\mathrm{HH})$ e para medição do desempenho das empresas deu-se preferência à Tipologia de Fleuriet. As seções 4 e 5 destinam-se ao detalhamento de ambas as técnicas selecionadas para condução da presente análise.

\section{4 ÍNDICES DE CONCENTRAÇÃO DE MERCADO}

De acordo com Rocha, Bueno e Pires (2007, p. 2), “[...] o Paradigma ECD considera a concentração de mercado como aspecto central na definição de estruturas de mercado, representando um papel importante na definição do desempenho alocativo dos mercados [...]". Assim, pode-se depreender que tais medidas de concentração pretendem captar a forma como os agentes econômicos apresentam um comportamento dominante em determinado mercado. Dessa maneira, os índices de concentração são indicadores que medem a concorrência existente em determinado mercado, podendo-se afirmar que quanto maior for o índice de concentração, menor é o grau de concorrência entre as 
empresas e, portanto, mais concentrado estará o poder de mercado (TIROLE, 1988; SCHERER e ROSS, 1990).

Com base em Scherer e Ross (1990) pode-se afirmar que existem basicamente três categorias de medidas de concentração: [1] medidas de concentração parciais ou sumárias que não utilizam os dados da totalidade das empresas em operação no setor escolhido para estudo, mas apenas uma parte delas; [2] medidas de concentração positivas que são determinadas unicamente em função da estrutura aparente do mercado industrial e não dependem de qualquer parâmetro comportamental, seja relativo aos produtores ou aos consumidores e; [3] medidas de concentração normativas que levam em conta, além da estrutura aparente, os parâmetros comportamentais relacionados com as preferências dos produtores ou dos consumidores.

Dentro desse contexto categórico, a presente investigação utiliza-se de uma medida de concentração parcial ou sumária denominada CR $(k)$ ou razão de concentração. Esse índice consiste na determinação da parcela de mercado das $k$ maiores empresas da indústria. Comumente se escolhe para valores de $k$, os números 4,8 e o total das empresas selecionadas, ou seja, no caso dessa pesquisa, a razão de concentração das quatro maiores indústrias de papel e celulose $C R_{4}$, para as oito maiores $C R_{8}$ e para as catorze maiores $C R_{14}$.

No entanto, deve-se salientar que alguns inconvenientes podem surgir com a utilização do $\mathrm{CR}(k)$, pelo fato de um desses índices poder representar diferentes estruturas, por exemplo, um $\mathrm{CR}_{4}$ de $48 \%$, pode representar 4 empresas de $12 \%$ de participação de mercado cada uma, como pode também, demonstrar que uma tenha $45 \%$ do mercado, enquanto outras participem somente $1 \%$ do setor, ou seja, as estruturas podem se apresentar com um grau muito elevado de diferenciação. Nesse artigo, esse problema não ocorreu porque não houve uma heterogeneidade muito exacerbada e nem trocas substanciais na posição das empresas, com relação a seu market share.

Para minimizar as possíveis limitações que podem influenciar a forma de mensuração das medidas de concentração de mercado pela metodologia CR $(k)$, também se optou pela utilização de um índice alternativo, designado Índice de Hirschman-Herfindahl $(\mathrm{HH})$. Tal indicador resulta do somatório dos quadrados das participações de mercado de cada empresa constante no mercado pesquisado. Isto ocorre porque, elevar cada parcela de mercado ao quadrado implica atribuir um peso maior às empresas relativamente maiores. Por fim, esse índice, varia de $1 / n$ ("n" é o número de empresas do mercado) a 1 e o limite superior está associado ao caso de monopólio e o inferior acontece quando todas as empresas têm o mesmo tamanho.

Além disso, índices de concentração de mercado considerando a participação das exportações das empresas no comércio internacional ou uma ponderação entre a participação do mercado interno e o externo, poderiam oferecer oportunidades para análises mais criteriosas. No entanto, a base de dados utilizada, não contém informações suficientes e individualizadas de cada empresa para tal cálculo.

\section{MODELAGEM DE FLEURIET: DESEMPENHO OPERACIONAL E FINANCEIRO}

Além das técnicas tradicionais por meio de índices de rentabilidade, de liquidez e estrutura de capitais ou análises horizontais e verticais, o desempenho de uma empresa pode ser avaliado por indicadores dinâmicos e analíticos, como por exemplo, a Modelagem de Fleuriet. Tal tipologia fornece informações a respeito do equilíbrio financeiro da empresa, por meio da identificação da necessidade de investimento no giro das operações 
da empresa e do volume de recursos permanentes necessário para o financiamento desse giro (SATO, 2007; SILVEIRA, ESPEJO e PERUCELO, 2008). Nessa tipologia Fleuriet faz combinações de três variáveis formando seis modelos de classificação quanto ao desempenho financeiro e operacional das organizações. São elas: [1] o Capital Circulante Líquido (CCL) ou Capital de Giro (CDG); [2] o Investimento Operacional em Giro (IOG) ou Necessidade de Capital de Giro (NCG) e; [3] o Saldo em Tesouraria (T). A Figura 3 demonstra essa combinação dos três elementos citados que formam a Modelagem de Fleuriet.

- Capital Circulante Líquido (CCL) resulta da diferença entre o passivo não circulante (PNC) e o ativo não circulante (ANC) e representa um conceito econômicofinanceiro, formando uma fonte de recursos permanentes, necessária para financiar a necessidade de capital de giro da empresa. O Investimento Operacional em Giro (IOG) resulta da diferença entre o Ativo Circulante Cíclico (ACC) e o Passivo Circulante Cíclico (PCC) e representa a aplicação permanente de fundos para financiar as atividades operacionais. Por fim, o Saldo em Tesouraria $(T)$, resulta da diferença entre o Ativo Circulante Financeiro (ACF) e o Passivo Circulante Oneroso (PCO) e demonstra os recursos de curto prazo que poderão sobrar ou faltar no caixa da empresa, com vistas a fazer frente aos seus compromissos, funcionando como um eficiente indicador da saúde financeira da empresa (FLEURIET, KEHDY e BLANC, 2003).

A tipologia empresarial segundo o Modelo Fleuriet (Figura 3) propicia a análise dinâmica do capital de giro por meio da evidenciação das políticas adotadas nos níveis tático $(\mathrm{T})$, operacional (IOG) e estratégico $(\mathrm{CCL})$.

\begin{tabular}{|c|c|c|c|c|c|}
\hline Tipo & $\mathrm{CCL}$ & IOG & Condição & $\mathrm{T}$ & Situação \\
\hline I & $>0$ & $<0$ & $\mathrm{CCL}>10 \mathrm{OG}$ & $>0$ & Excelente \\
\hline II & $>0$ & $>0$ & $\mathrm{CCL}>10 \mathrm{OG}$ & $>0$ & Sólida \\
\hline III & $<0$ & $<0$ & $\mathrm{CCL}>10 \mathrm{OG}$ & $>0$ & Arriscada \\
\hline IV & $>0$ & $>0$ & $\mathrm{CCL}<10 \mathrm{OG}$ & $<0$ & Insatisfatória \\
\hline V & $<0$ & $<0$ & $\mathrm{CCL}<10 \mathrm{OG}$ & $<0$ & Ruim \\
\hline VI & $<0$ & $>0$ & $\mathrm{CCL}<10 \mathrm{OG}$ & $<0$ & Péssima \\
\hline
\end{tabular}

Figura 3 - Tipologia de Empresas segundo o Modelo Fleuriet Fonte: Adaptado de Braga (1991)

$\mathrm{Na}$ realidade dinâmica das empresas, as contas do ativo e do passivo são classificadas conforme o tempo que levam para a realização de um ciclo. Algumas contas apresentam movimentação mais lenta, podendo ser consideradas permanentes ou nãocíclicas. O movimento de outras contas, no entanto, com movimento relacionado ao ciclo operacional do negócio, pode ser denominado contínuo ou cíclico (FLEURIET, KEHDY e BLANC, 2003).

\section{DESIGN DA PESQUISA DE CAMPO}

Conforme Cooper e Schindler (2003) o presente artigo pode ser categorizado como: [1] estudo formal, quanto ao grau em que a questão de pesquisa foi cristalizada; [2] ex 
post facto, quanto ao poder do pesquisador de produzir efeitos nas variáveis que estão sendo estudadas; [3] descritivo e causal, pois, além de descrever as características de uma determinada amostra, tem como foco estabelecer se há um relacionamento de causa e efeito entre as variáveis investigadas e; [4] longitudinal porque é feito em um período de cinco anos.

A fonte de dados utilizada para identificação e classificação das indústrias de papel e celulose brasileiras foi o banco de dados da BRACELPA - Associação Brasileira de Celulose e Papel que divulga anualmente um relatório estatístico que demonstra a evolução e desempenho dos setores escolhidos. A amostra foi escolhida de forma intencional cujo critério utilizado foi a classificação das catorze maiores empresas do setor de celulose e papel, por produção. Esse ranking foi retirado do relatório estatístico do ano de 2007 e representaram nessa ocasião $94 \%$ e $63 \%$ da produção de celulose e papel, respectivamente, no Brasil.

Optou-se pela utilização do CR $(k)$ e do índice de Hirschman-Herfindahl $(\mathrm{HH})$ para mensurar a concentração de mercado da celulose e papel. Para esse cálculo foi considerado o valor da produção total de celulose e papel do período. Para cálculo de desempenho foram utilizados os demonstrativos contábeis publicados por essas empresas selecionadas na CVM - Comissão de Valores Mobiliários. A escolha do período compreendido entre 2003 a 2007 foi decorrente da disponibilidade e padronização das informações dos relatórios da BRACELPA - Associação Brasileira de Celulose e Papel por questões de acessibilidade de dados.

\section{RESULTADOS E DISCUSSÕES}

A presente seção destina-se à apresentação dos resultados obtidos dos índices de concentração dos mercados de papel e celulose no Brasil durante os anos de 2003 e 2007 e o desempenho com base na Tipologia de Fleuriet, suportado por seus três indicadores basilares: capital circulante líquido (CCL), investimento operacional em giro (IOG) e saldo em tesouraria $(T)$. Salienta-se, porém, que tais análises foram realizadas apenas para as 4 maiores empresas $\left(\mathrm{CR}_{4}\right)$, pois, possuem seus demonstrativos econômico-financeiros publicados na CVM (com exceção da International Paper do Brasil Ltda). Constatou-se que essa análise sairia prejudicada com as empresas constantes no $C_{8}$ e $C_{14}$, porque tais corporações não divulgam suas informações aos usuários externos.

\section{1 ÍNDICES DE CONCENTRAÇÃO DE MERCADO}

Optou-se em dividir esse tópico da pesquisa em mais três, devido às particularidades dos setores escolhidos para a análise. A maioria das empresas constantes no $\mathrm{CR}_{4}, \mathrm{CR}_{8}$ e $\mathrm{CR}_{14}$, do mercado de celulose, também se inserem nestas mesmas classificações do mercado de papel. Portanto, ponderou-se que, além de calcular os índices de concentração de mercado para esses dois setores, também, era necessário calculá-los para o mercado de papel e celulose como um todo. Tal cálculo foi realizado somando-se as produções dos períodos analisados, perfazendo-se assim, uma média do setor.

\subsection{1 Índices de concentração do mercado de celulose}

Constata-se por meio da Tabela 2 e do Gráfico 1, que o mercado de celulose no Brasil é bastante concentrado. As quatro maiores empresas do setor $\left(\mathrm{CR}_{4}\right)$ detinham em 2003, 62,92\% do mercado total de celulose, caindo para 61,09\% em 2007, porém, 
verificam-se pequenas modificações no grau de concentração dessas empresas. Em contrapartida, o índice de concentração das oito maiores empresas do setor de celulose $\left(\mathrm{CR}_{8}\right)$, indicou uma tendência de aumento no nível de concentração de mercado, passando de 81,26\% em 2003 para 84,68\% em 2007. Finalmente, verificou-se que 14 empresas detinham aproximadamente $95 \%$ deste mercado, sinalizando um baixo grau de pulverização.

Por fim, o indicador $\mathrm{HH}$, diferentemente do $\mathrm{CR}(k)$, porque é referente à totalidade de empresas do setor de celulose e não somente à parte delas, apresenta resultados semelhantes, pois, não variou de modo significante durante o período avaliado. Em 2007 deu-se a maior queda neste índice, demonstrando que aumentou o grau de competição entre as empresas nesse mercado.

Tabela 2 - Concentração de Mercado de Celulose: 2003 a 2007

\begin{tabular}{|c|c|c|c|c|c|c|c}
\hline \multicolumn{7}{c}{ Celulose } \\
\hline ANO & Produção & CR4 (\%) & Produção & CR8 (\%) & Produção & CR14 (\%) & HH \\
\hline 2003 & 5.706 .281 & $62,92 \%$ & 7.369 .934 & $81,26 \%$ & 8.376 .798 & $92,36 \%$ & 0,1310 \\
\hline 2004 & 6.089 .104 & $63,30 \%$ & 7.813 .065 & $81,22 \%$ & 8.993 .541 & $93,49 \%$ & 0,1336 \\
\hline 2005 & 6.473 .194 & $62,53 \%$ & 8.472 .037 & $81,84 \%$ & 9.729 .553 & $93,99 \%$ & 0,1334 \\
\hline 2006 & 7.107 .594 & $63,57 \%$ & 9.239 .484 & $82,64 \%$ & 10.574 .818 & $94,59 \%$ & 0,1363 \\
\hline 2007 & 7.329 .386 & $61,09 \%$ & 10.159 .917 & $84,68 \%$ & 11.336 .523 & $94,49 \%$ & 0,1288 \\
\hline
\end{tabular}

Fonte: Dados organizados pelos autores com base na pesquisa

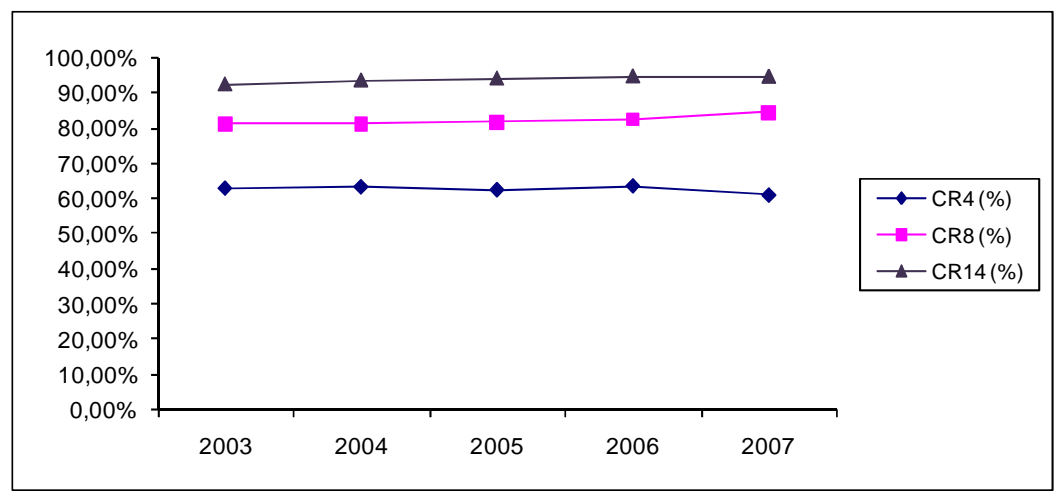

Gráfico 1 - Concentração de Mercado de Celulose - CR (k): 2003 a 2007

Fonte: Dados organizados pelos autores com base na pesquisa

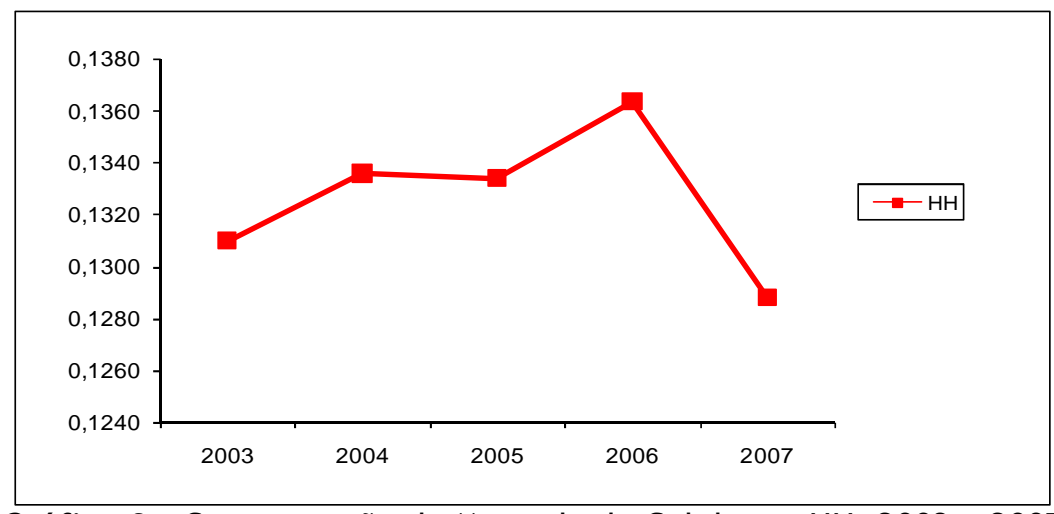

Gráfico 2 - Concentração de Mercado de Celulose - HH: 2003 a 2007

Fonte: Dados organizados pelos autores com base na pesquisa 
Outra comprovação relevante é a de que as 4 maiores empresas do setor de celulose $\left(\mathrm{CR}_{4}\right)$ não se alteraram nos 5 anos analisados, havendo somente mudanças com relação às suas posições no ranking. Estas 4 empresas são: Aracruz Celulose S/A, Suzano Papel e Celulose, Votorantim Celulose e Papel S/A e Klabin S/A.

\subsection{2 Índices de concentração de mercado de papel}

De modo similar ao item anterior, a Tabela 3 e o Gráfico 2, mostram o comportamento dos índices de concentração de mercado do setor de papel. Nesta esfera da economia, verificou-se que as 4 maiores empresas do setor $\left(C_{4}\right)$ detiveram nos anos analisados um percentual inferior a $50 \%$ do mercado, diferentemente do setor de celulose que se mostrou com maior concentração. Percebeu-se também que, dos anos de 2003 a 2005, houve uma redução nos três CRk discutidos, evidenciando uma tendência de desconcentração para o setor. Esse fato começou a ser revertido em 2007 para as 4 maiores empresas do setor papeleiro $\left(C_{4}\right)$ e em 2006 para as 14 maiores empresas $\left(C_{14}\right)$. Por fim, verificou-se que contrariamente ao setor de celulose, que se apresentou bastante concentrado, as 14 maiores indústrias papeleiras $\left(\mathrm{CR}_{14}\right)$ detinham aproximadamente $63 \%$, deixando um espaço maior para entrada de novos concorrentes.

Com relação aos índices $\mathrm{HH}$, pode-se visualizar por meio da Tabela 3 e do Gráfico 4 que de 2003 a 2005 houve um aumento gradativo, mostrando que o grau de competição entre as empresas de papel diminuía. Isso mudou em 2004, quando esse indicador caiu de maneira considerável, culminando em 0,1966 no ano de 2007, indicando que gradualmente o espaço competitivo entre as empresas de papel foi retomando o crescimento. Convém lembrar que essa análise não pode ser comparada com o CR $(k)$, visto se tratar da totalidade de empresas no setor de papel brasileiro.

Tabela 3 - Concentração de Mercado de Papel: 2003 a 2007

\begin{tabular}{c|c|c|c|c|c|c|c}
\hline \multicolumn{7}{c}{ Papel } \\
\hline ANO & Produção & CR4 (\%) & Produção & CR8 (\%) & Produção & CR14 (\%) & HH \\
\hline 2003 & 3.395 .814 & $42,90 \%$ & 4.140 .093 & $52,30 \%$ & 4.833 .272 & $61,06 \%$ & 0,2096 \\
\hline 2004 & 3.461 .816 & $40,96 \%$ & 4.227 .856 & $50,02 \%$ & 5.017 .147 & $59,36 \%$ & 0,2184 \\
\hline 2005 & 3.509 .349 & $40,82 \%$ & 4.267 .006 & $49,63 \%$ & 5.070 .869 & $58,98 \%$ & 0,2207 \\
\hline 2006 & 3.512 .866 & $40,26 \%$ & 4.497 .515 & $51,55 \%$ & 5.280 .831 & $60,53 \%$ & 0,2093 \\
\hline 2007 & 3.764 .898 & $41,79 \%$ & 4.750 .624 & $52,74 \%$ & 5.633 .486 & $62,54 \%$ & 0,1966 \\
\hline
\end{tabular}

Fonte: Dados organizados pelos autores com base na pesquisa

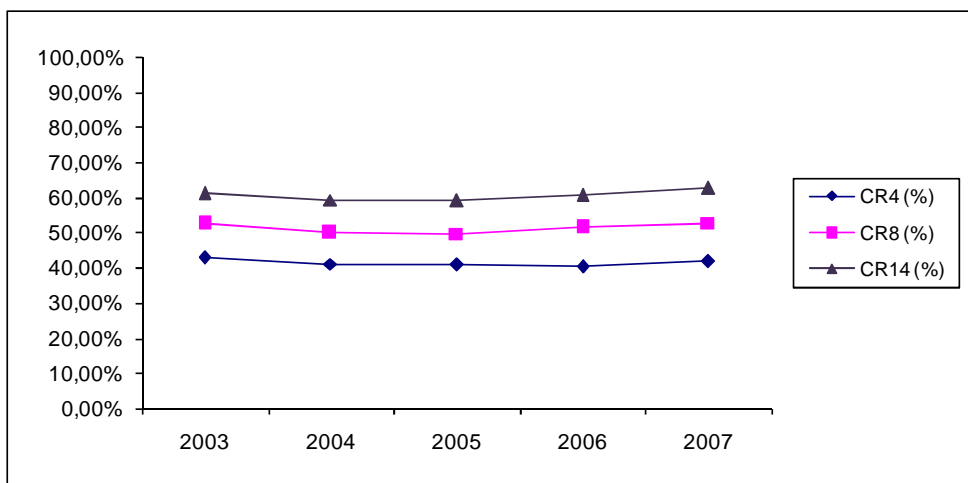

Gráfico 3 - Concentração de Mercado de Papel - CR (k): 2003 a 2007

Fonte: Dados organizados pelos autores com base na pesquisa 


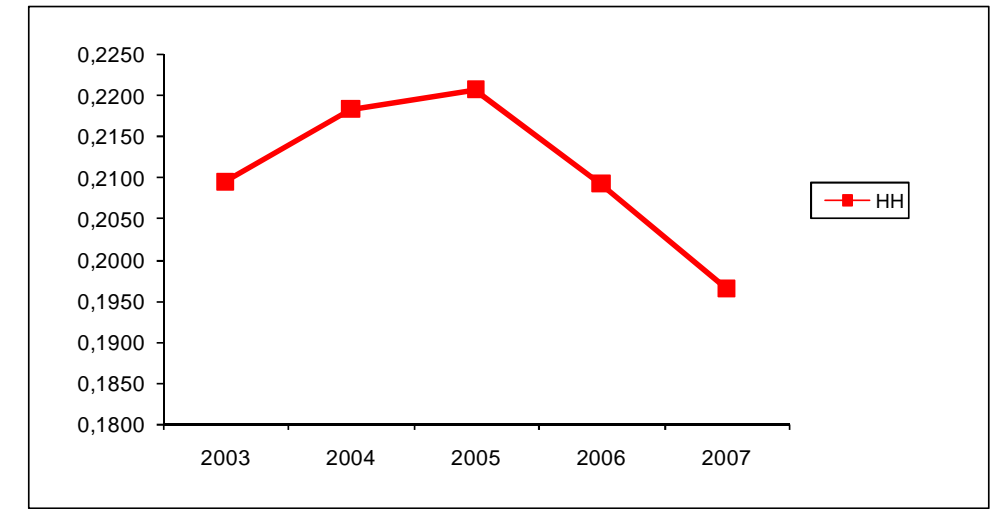

Gráfico 4 - Concentração de Mercado de Papel - HH: 2003 a 2007

Fonte: Dados organizados pelos autores com base na pesquisa

Uma constatação semelhante à anteriormente realizada para o mercado de celulose é a de que as quatro maiores empresas também não se alteram ao longo dos anos, somente suas posições no ranking. Outro fato importante é que 3 das 4 maiores empresas de celulose também o são no ramo de papel - Suzano Papel e Celulose, Votorantim Celulose e Papel S/A e Klabin S/A - e somente a Aracruz Celulose S/A não está presente entre as 4 maiores do setor papeleiro, cedendo espaço para a International Paper do Brasil Ltda.

\subsection{3 Índices de concentração de mercado de celulose e papel}

Devido à inter-relação existente entre os dois setores econômicos - celulose e papel - primeiramente pelo fato da celulose ser a matéria-prima principal para a produção do papel e também pelo fato das maiores empresas trabalharem com ambos os produtos e formarem uma rede comum de produção, verificou-se a necessidade de se apurar a concentração de mercado comum dos dois produtos selecionados para análise.

A Tabela 4 e o Gráfico 3 desvelam que as 4 maiores empresas de celulose e papel $\left(C_{4}\right)$, já citadas a anteriori, foram responsáveis pela produção de aproximadamente $50 \%$ desses produtos durante os anos de 2003 a 2007. Observa-se, também que, enquanto houve uma tendência de desconcentração do $\mathrm{CR}_{4}$, as 8 maiores empresas do ramo $\left(\mathrm{CR}_{8}\right)$ obtiveram um aumento no nível de concentração do setor, tal fato parece demonstrar que esse mercado está se desconcentrando em favor das 8 e 14 maiores empresas, saindo do controle de poucas organizações, aumentando assim, a concorrência do setor analisado. $\mathrm{O}$ índice $\mathrm{HH}$, por sua vez, confirma esse resultado, pois, apesar de aumentar nos dois primeiros anos, após 2005 representa uma trajetória de suaves decréscimos para o setor de celulose e papel durante o período compreendido entre 2003 e 2007.

Tabela 4 - Concentração de Mercado de Celulose e Papel: 2003 a 2007

\begin{tabular}{c|c|c|c|c|c|c|c}
\hline \multicolumn{7}{c}{ Celulose e Papel } \\
\hline ANO & Produção & CR4 (\%) & Produção & CR8 (\%) & Produção & CR14 (\%) & HH \\
\hline 2003 & 8.492 .298 & $50,00 \%$ & 10.943 .412 & $64,43 \%$ & 12.513 .648 & $73,68 \%$ & 0,1216 \\
\hline 2004 & 8.813 .740 & $49,00 \%$ & 11.314 .814 & $62,91 \%$ & 12.970 .570 & $72,11 \%$ & 0,1221 \\
\hline 2005 & 9.150 .379 & $48,74 \%$ & 11.915 .099 & $63,47 \%$ & 13.625 .179 & $72,58 \%$ & 0,1196 \\
\hline 2006 & 9.661 .108 & $49,50 \%$ & 12.486 .934 & $63,98 \%$ & 14.455 .323 & $74,06 \%$ & 0,1154 \\
\hline 2007 & 9.578 .771 & $48,13 \%$ & 12.999 .635 & $65,32 \%$ & 14.785 .271 & $74,30 \%$ & 0,1119 \\
\hline
\end{tabular}

Fonte: Dados organizados pelos autores com base na pesquisa 


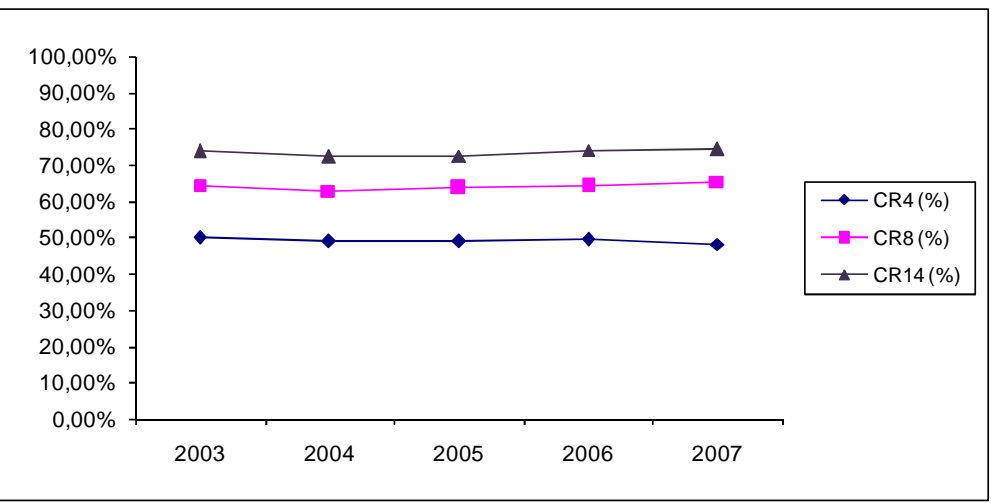

Gráfico 5 - Concentração de Mercado de Celulose e Papel - CR (k): 2003 a 2007

Fonte: Dados organizados pelos autores com base na pesquisa

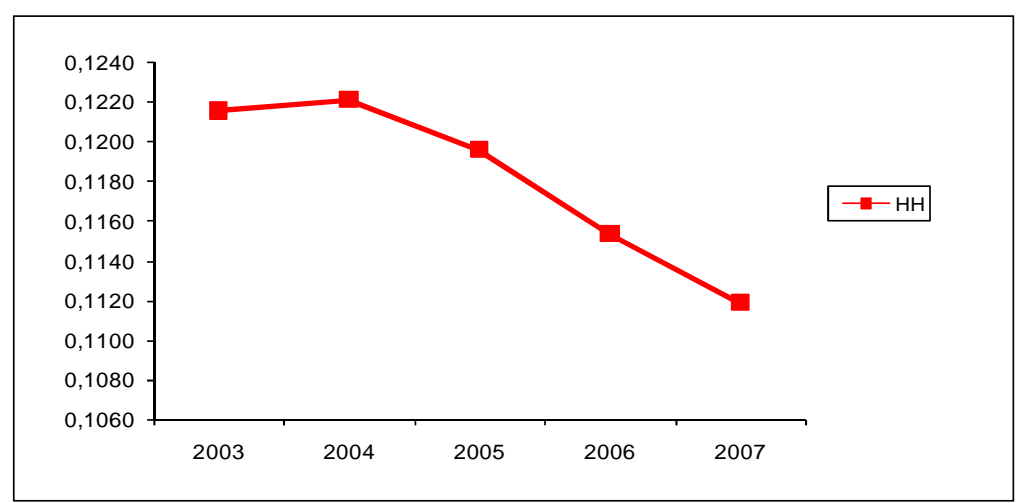

Gráfico 6 - Concentração de Mercado de Celulose e Papel - HH: 2003 a 2007 Fonte: Dados organizados pelos autores com base na pesquisa

Pode-se depreender que o setor de papel e celulose como um todo é altamente concentrado. As consequências dessa alta concentração podem influenciar o desempenho das empresas de duas formas: [1] em setores altamente concentrados, o reduzido número de empresas pode "combinar" entre si acordos, de forma tácita ou explícita, ao reduzirem a produção a um nível que elimine o poder competitivo, deixando os preços abaixo do nível de competitividade (TIROLE, 1988) e; [2] a alta concentração dos setores também pode conduzir a heterogeneidade de desempenho em função das economias de escala, ou seja, em ramos concentrados, onde há economias de escala, apenas esse número reduzido de empresas participantes obterá vantagem competitiva com essas economias, pois, manterão seus custos mais baixos do que as firmas menores, enquanto todos os demais fatores permanecerão constantes, levando à heterogeneidade de desempenho (BARNEY e HESTERLY, 2004). A próxima seção trata do desempenho das empresas analisadas, constantes no $\mathrm{CR}_{4}$.

\subsection{DESEMPENHO OPERACIONAL E FINANCEIRO}

Nessa seção encontra-se a análise de desempenho operacional e financeiro das 4 maiores empresas do setor de papel e celulose $\left(C_{4}\right)$, por meio da Tipologia de Fleuriet, com exceção da International Paper do Brasil Ltda que não possui suas informações divulgadas na CVM. A Tabela 5 resume as informações do desempenho, apresentando os valores de $\mathrm{CCL}$, IOG e $\mathrm{T}$ das maiores empresas, para o período analisado. 
Tabela 5 - Desempenho Operacional e Financeiro CR - Papel e Celulose: 2003 a 2007 (em milhares de reais)

\begin{tabular}{|c|c|c|c|c|c|c|}
\hline \multirow[b]{2}{*}{ ANO } & \multirow[b]{2}{*}{ Empresas } & \multicolumn{5}{|c|}{ DESEMPENHO POR MEIO DA TIPOLOGIA DE FLEURIET } \\
\hline & & $T$ & CCL & IOG & Tipo & Situação \\
\hline \multirow{4}{*}{2003} & Klabin & -52.442 & 571.614 & 624.056 & IV & Insatisfatória \\
\hline & Aracruz & -514.861 & 279.165 & 794.026 & IV & Insatisfatória \\
\hline & \begin{tabular}{|l|} 
Suzano \\
\end{tabular} & -238.495 & 406.098 & 644.593 & IV & Insatisfatória \\
\hline & \begin{tabular}{|l|} 
Votorantim \\
\end{tabular} & -385.289 & 219.195 & 604.484 & IV & Insatisfatória \\
\hline \multirow{4}{*}{2004} & Klabin & 556.403 & 1.194 .783 & 638.380 & II & Sólida \\
\hline & Aracruz & 565.402 & 1.303 .852 & 738.450 & II & Sólida \\
\hline & \begin{tabular}{|l|} 
Suzano \\
\end{tabular} & 187.023 & 1.037 .926 & 850.903 & II & Sólida \\
\hline & \begin{tabular}{|l|} 
Votorantim \\
\end{tabular} & -552.938 & 93.052 & 645.990 & IV & Insatisfatória \\
\hline \multirow{4}{*}{2005} & Aracruz & 243.729 & 1.323 .194 & 1.079 .465 & II & Sólida \\
\hline & \begin{tabular}{|l|} 
Klabin \\
\end{tabular} & 752.733 & 1.216 .803 & 464.070 & II & Sólida \\
\hline & \begin{tabular}{|l|} 
Suzano \\
\end{tabular} & -51.091 & 979.437 & 1.030 .528 & IV & Insatisfatória \\
\hline & Votorantim & 708.022 & 1.451 .856 & 743.834 & II & Sólida \\
\hline \multirow{4}{*}{2006} & Aracruz & 738.123 & 1.787 .597 & 1.049 .474 & II & Sólida \\
\hline & Klabin & 1.564 .844 & 2.069 .815 & 504.971 & II & Sólida \\
\hline & Suzano & 842.404 & 1.984 .245 & 1.141 .841 & II & Sólida \\
\hline & Votorantim & 554.872 & 1.439 .593 & 884.721 & II & Sólida \\
\hline \multirow{4}{*}{2007} & Aracruz & 384.161 & 1.466 .334 & 1.082 .173 & II & Sólida \\
\hline & Klabin & 1.704 .205 & 2.090 .837 & 386.632 & II & Sólida \\
\hline & \begin{tabular}{|l|} 
Suzano \\
\end{tabular} & 494.025 & 1.769 .390 & 1.275 .365 & II & Sólida \\
\hline & \begin{tabular}{|l|} 
Votorantim \\
\end{tabular} & 415.138 & 1.042 .079 & 626.941 & II & Sólida \\
\hline
\end{tabular}

Fonte: Dados organizados pelos autores com base na pesquisa

Pode-se observar por meio da Tabela 5 que as 4 maiores empresas que possuem desde o início do período analisado, uma posição de destaque no setor de papel e celulose, vêm aumentando gradativamente seu desempenho operacional e financeiro. Todas saíram de uma posição do Tipo IV - insatisfatória, segundo a Tipologia de Fleuriet, para uma posição do Tipo II - sólida, corroborando com as assertivas anteriormente mencionadas de que em mercados altamente concentrados, as empresas dominantes, tendem a apresentar maior desempenho (TIROLE, 1988; SCHERER e ROSS, 1990; BARNEY e HESTERLY, 2004).

\subsubsection{Aracruz Celulose S/A}

A empresa Aracruz Celulose S/A, se apresentou em 2007 como a maior produtora de celulose brasileira, posição que ocupa desde 2005. Em 2003, a empresa encontrava-se em posição insatisfatória, de acordo com a classificação tipológica de Fleuriet, devido ao valor de seu Saldo em Tesouraria ( $T$ ) ser negativo, indicando que a Aracruz possuía fontes de recursos de curto prazo, financiando as atividades operacionais da empresa, ou seja, que o capital de giro (CCL) era insuficiente para cobrir a necessidade de capital de giro (IOG). 0 Gráfico 4, ilustra esses resultados para uma melhor visualização.

No decorrer dos anos, a situação da empresa passou de insatisfatória para sólida (Tipo II de Fleuriet), porém, sempre com uma necessidade de capital de giro positiva (IOG), o que representa que as aplicações no ACC são superiores as fontes de recursos do PCC, gerando necessidade de recursos, para as quais a empresa deve obter outras fontes de recursos, que podem ser próprias e/ou de terceiros. 


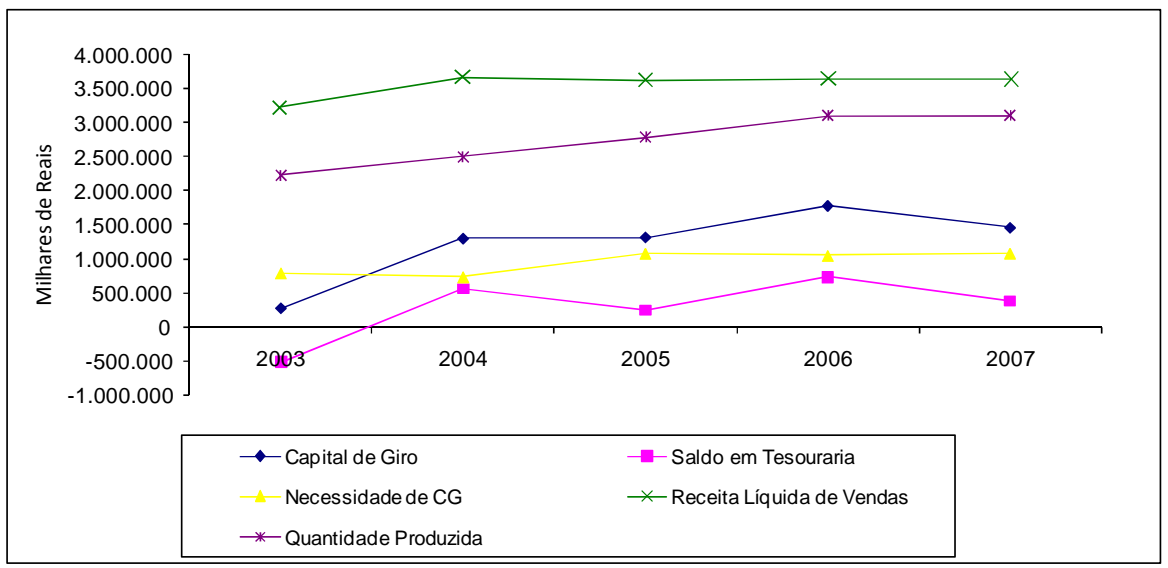

Gráfico 7 - Desempenho Operacional e Financeiro - Aracruz Celulose S/A: 2003 a 2007 Fonte: Dados organizados pelos autores com base na pesquisa

Por fim, verificou-se que nos 5 anos analisados, o capital de giro (CCL) manteve-se positivo e crescendo, demonstrando que a liquidez da empresa aumentava enquanto, as possibilidades de apresentar situação de desequilíbrio financeiro diminuíam. Esse aumento de desempenho ao longo dos anos pode ser explicado pelo aumento da concentração de mercado da Aracruz que em 2003 detinha 24,57\% do mercado de celulose brasileiro e em 2006, contava com uma fatia de 27,74\% de market share, caindo para 25,81\% em 2007. Salienta-se ainda que esta empresa não é participante do mercado de papel, que poderia lhe dar um aumento expressivo de mercado, como ocorre com a Klabin, Suzano e Votorantim.

\subsubsection{Klabin S/A}

De modo análogo, o Gráfico 5 mostra o desempenho operacional e financeiro da empresa Klabin S/A, que das 4 maiores empresas do setor de papel e celulose, foi a que demonstrou um maior aumento de desempenho em função da concentração de mercado, saindo também de uma situação do Tipo IV em 2003 para uma posição sólida em 2007.

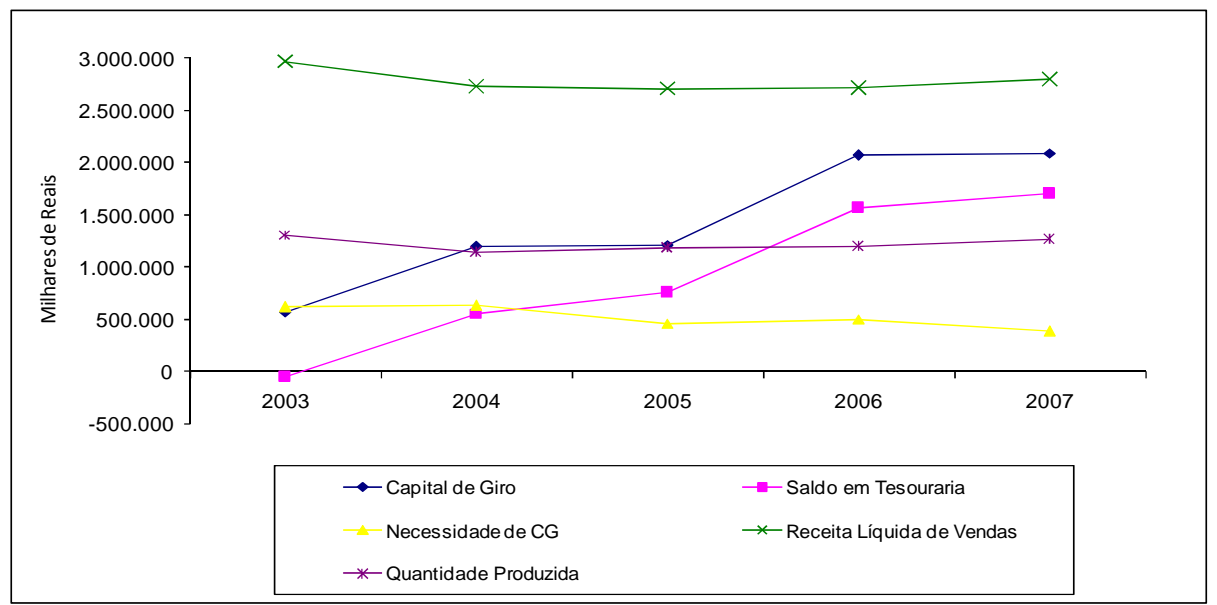

Gráfico 8 - Desempenho Operacional e Financeiro - Klabin S/A: 2003 a 2007 Fonte: Dados organizados pelos autores com base na pesquisa

O saldo em tesouraria (T) aumentou de 2003 para 2007, saindo de uma posição deficitária para uma posição superavitária, conforme demonstra a Tabela 5. 0 mesmo ocorreu com o capital de giro (CCL) que apresentou o mesmo comportamento que o saldo em tesouraria. Em contraposição, a necessidade de capital de giro (IOG), diminuiu de forma a deixar a Klabin em uma situação bem mais favorável financeiramente. Destaque- 
se que a Klabin S/A participa com elevado percentual dos mercados de celulose e papel, porém, sua maior concentração e participação estão no setor papeleiro.

\subsubsection{Suzano Papel e Celulose}

A empresa Suzano foi a única das 4 maiores do setor de celulose e papel que saiu de uma situação deficitária de saldo em tesouraria (T) de 2003 para 2004 e em 2005 retornou a essa mesma situação, recuperando-se em 2006. Fato esse que fez com que ficasse em uma posição insatisfatória, conforme Tipologia de Fleuriet, para os anos de 2003 e 2005. 0 Gráfico 6 ilustra as informações operacionais e financeiras da Suzano Papel e Celulose.

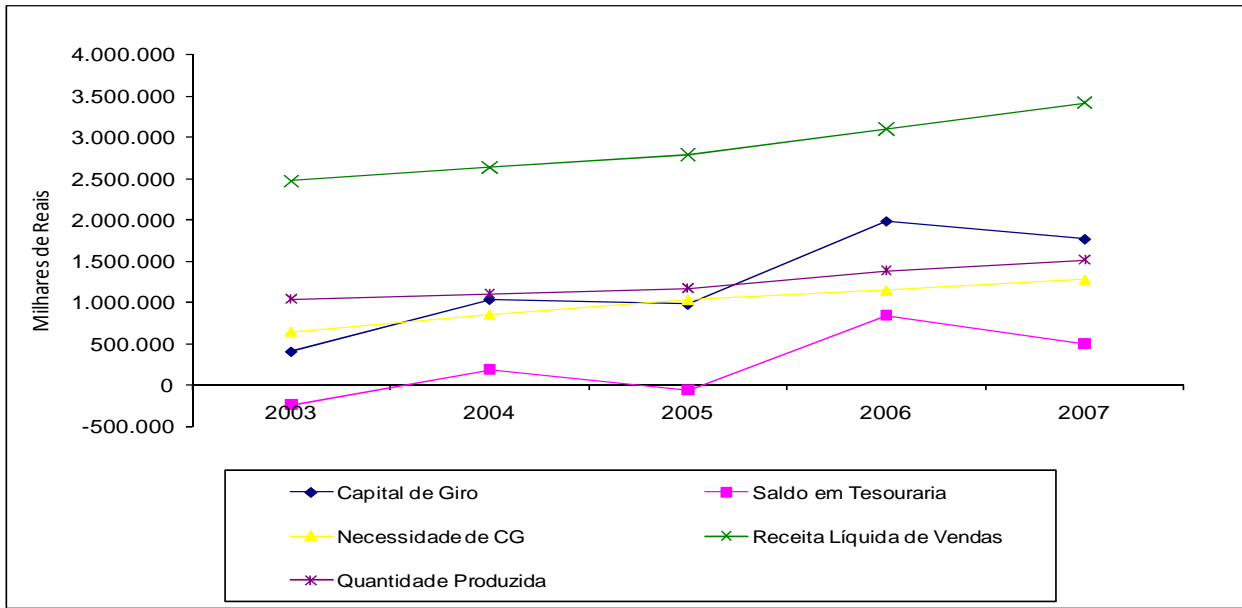

Gráfico 9 - Desempenho Operacional e Financeiro - Suzano Papel e Celulose: 2003 a 2007

Fonte: Dados organizados pelos autores com base na pesquisa

A Suzano Papel e Celulose obteve um desempenho exemplar em 2006, com um aumento significativo do capital de giro $(C C L)$ e do saldo em tesouraria $(T)$ e uma pequena diminuição da necessidade de capital de giro (IOG). Tal fato ocorreu devido à aquisição de $50 \%$ da fabricante de papel Ripasa, adquirida em 2005, em parceria com a VCP, empresa do grupo Votorantim. Em 2007, a Suzano apresentou indicadores importantes para seu crescimento, segundo a Revista Exame, foi o segundo lugar em crescimento do setor $(16 \%)$, fortalecendo sua posição no mercado.

A empresa também aproveitou o aquecimento do mercado mundial, graças, sobretudo ao aumento da demanda chinesa e dos países emergentes, exportando em 2007, praticamente $80 \%$ de sua produção de celulose. Perante a revista exame, a Suzano, foi considerada a melhor empresa de 2007, porque acelerou suas aquisições, ampliou sua produção e se fortaleceu para a competição no mercado internacional de celulose, apesar de ainda estar atrás da Aracruz, que continua sendo a maior empresa de celulose do Brasil.

\subsubsection{Votorantim Celulose e Papel S/A}

Similarmente às empresas anteriores, a Votorantim Celulose e Papel S/A saiu de uma situação deficitária de caixa em 2003 e 2004, recuperando-se ano a ano até o final do período analisado (2007) quando apresentou uma situação superavitária de caixa. Tal fato pode ser ratificado por meio da análise do saldo em tesouraria $(\mathrm{T})$ do período. Devido à ocorrência desse fato, a empresa analisada, nos exercícios de 2003 e 2004, apresentou uma situação insatisfatória (Tipologia de Fleuriet), recuperando-se de 2005 a 2007, quando apresentou uma posição do Tipo II - sólida. O Gráfico 7 demonstra os dados de desempenho operacional e financeiro da Votorantim Celulose e Papel S/A. 


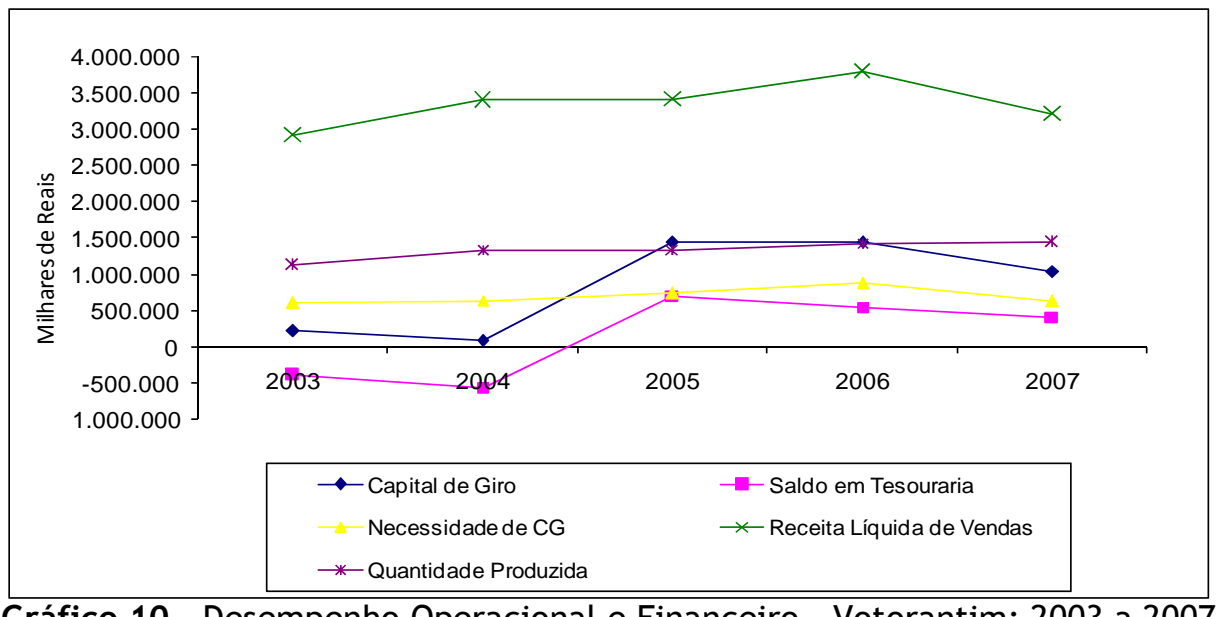

Gráfico 10 - Desempenho Operacional e Financeiro - Votorantim: 2003 a 2007

Fonte: Dados organizados pelos autores com base na pesquisa

O capital circulante líquido (CCL) aumentou de maneira considerável em 2005 e 2006 e a necessidade de capital de giro (IOG) permaneceu positiva em todos os anos. Remontando ao que já foi mencionado, a Votorantim, melhorou seu desempenho e conseqüente participação no mercado, devido à sua parceria com a Suzano, na aquisição de $50 \%$ da Ripasa. Em 2007, a Votorantim, foi considerada a terceira maior empresa do setor de papel e celulose, pela Revista Exame e também, a empresa que mais gerou riqueza por empregado - em torno de 225.448 dólares por empregado.

\subsection{ANÁLISE ESTRUTURA-DESEMPENHO}

Seguindo as manifestações interpostas por Geroski (1982), de que uma análise atenta das propriedades e dos modelos estatísticos entre os índices de concentração e o desempenho permite que se evite: inferências causais incorretas, imposição de regras e políticas sobre os dados obtidos, suposições não testadas e injustificadas daquilo que pode ser verificado diretamente, e ainda de que, "[...] há muito mais informação a ser extraída de conjunto de dados que apenas coeficientes positivos em modelos lineares [...]" (GEROSKI, 1982, p. 7), o presente estudo elabora uma análise gráfica e visual dos dados obtidos durante a pesquisa.

Primeiramente, deve-se ressaltar que a análise efetuada neste estudo excluiu do Paradigma ECD a variável intermediária que é a conduta, portanto, esse impacto deve ser considerado no estudo. Tal fato justifica-se por se tratar de uma pesquisa que remonta à pesquisa original de Bain (1951) que considerou a conduta ou barreiras à entrada, inserindo o conceito de "preço-limite" e concluiu que as barreiras à entrada explicam parte da taxa de lucro somente nas indústrias altamente concentradas. Assim, Bain (1951) analisou somente a relação entre a estrutura e o desempenho, pois considerou a conduta um conceito endógeno à própria estrutura. Não obstante, os estudos sobre oligopólios já não conseguem mais se separar das barreiras à entrada, tornando-se uma peça fundamental para explicar a dinâmica dos mercados. Portanto, a eliminação da conduta é uma das limitações do Paradigma ECD e conseqüentemente desta pesquisa.

Uma das principais exigências para se testar a validade do Paradigma ECD é que a escolha da variável desempenho é fundamental. Na presente pesquisa utilizou-se a Tipologia de Fleuriet para avaliação do desempenho financeiro e operacional, que sumariza em uma variável categórica o saldo em tesouraria (T), o capital circulante líquido $(C C L)$ e a necessidade de capital de giro (IOG), mas impossibilita que tal seja tirada qualquer relação com a concentração de mercado, visto que, cada tipologia categórica de desempenho é fundamentada pela Figura 3 , ou seja, única e exclusivamente pelo sinal 
positivo ou negativo das variáveis que a compõem. 0 ideal é que fossem escolhidas variáveis de desempenho como lucratividade, rentabilidade, retorno sobre o patrimônio líquido, etc.

Percebe-se graficamente que os índices de concentração utilizados estão mostrando as mesmas tendências e que ao final do período, para as empresas analisadas constantes do grupo $\mathrm{CR}_{4}$, observa-se uma desconcentração do mercado de celulose e uma pequena concentração do mercado de papel, perfazendo com que no mercado de celulose e papel como um todo houvesse uma pequena desconcentração e um aumento concorrencial. Quanto ao desempenho dessas empresas, verifica-se que começaram com uma posição insatisfatória e migraram no ano subseqüente para uma posição solida, assim permanecendo por todos os períodos analisados. Importante ressaltar que a Tipologia de Fleuriet estabelece grande ênfase para o capital próprio. Sob esse enfoque, pode-se afirmar que essas empresas, em um cenário de aumento de competição, adotaram atenção especial para a liquidez em suas organizações.

Outro fator importante a ser destacado e limitador desse estudo é a conclusão do estudo de Medeiros e Rodrigues (2004) que testaram a Tipologia de Fleuriet e constataram que base da separação proposta por Fleuriet entre ativos e passivos financeiros (erráticos) e ativos e passivos cíclicos (operacionais) não são válidas, pois todas as variáveis consideradas são relacionadas com as operações das empresas. Portanto, sem essa segregação, deveriam ser analisados o ativo circulante e passivo circulante integralmente, caindo no modelo convencional de análise de capital de giro e os resultados encontrados na presente pesquisa, com base em Fleuriet, não implicam necessariamente em retornos superiores sobre o capital das empresas em estudo, no período em análise.

Portanto, por meio das análises parciais dos itens 7.1 e 7.2 pode-se depreender que não há possibilidades neste estudo de dimensionar a relação existente entre a concentração de mercado e o desempenho em termos de influência simples ou mútua entre essas variáveis, porque, mesmo com a diferença entre a concentração de mercado das empresas, o desempenho permaneceu o mesmo, com a mesma tipologia delineada por Fleuriet.

\section{CONSIDERAÇÕES FINAIS}

As discussões propostas no artigo foram encontrar subsídios para responder à questão de pesquisa e identificar se existe alguma relação entre a concentração de mercado (estrutura) e o desempenho das empresas, por meio da Tipologia de Fleuriet. Pondera-se que essa análise fica delimitada, ao período analisado, às 4 maiores empresas do setor de celulose e papel, devido ao fato de algumas das demais empresas não possuírem suas informações divulgadas na CVM, no âmbito da abordagem proposta.

Em resposta a tal questionamento, os resultados estão circunscritos ao modelo proposto por Fleuriet, com enfoque na liquidez das organizações. Portanto, como sugestão para pesquisas futuras, propõe-se a escolha de variáveis que melhor explicitem o desempenho tais como: lucratividade, rentabilidade, retorno sobre os ativos, etc. Também se sugere uma investigação científica quantitativa com métodos estatísticos consistentes, que provem por meio de métodos multivariados e econométricos essa relação entre a estrutura de concentração de mercado e o desempenho e também uma análise longitudinal mais ampla, com 10 ou 15 anos, a fim de aprofundar mais as análises aqui realizadas. Também se sugere que seja adicionado o fator intermediário (conduta) ao Paradigma Estrutura-Conduta-Desempenho (ECD), para a análise completa da teoria proposta por Mason (1939) e Bain (1959). 
Por fim, destaca-se que este estudo possui implicações tanto acadêmicas quanto profissionais. Estas contribuições surgem na medida em que se observa que este estudo diferencia-se dos demais efetuados sobre essa temática porque traz em seu bojo a constatação das limitações que pode trazer a escolha de uma metodologia inadequada de mensuração de qualquer uma das variáveis para a análise do Paradigma Estrutura-CondutaDesempenho.

\section{REFERÊNCIAS}

ADAMI, Andréia Cristina de Oliveira; MORAES, Márcia Azanha Ferraz Dias de. Setor exportador de carne bovina brasileiro: A estrutura afeta a conduta? In: XLII CONGRESSO DA SOBER - Instituições, Eficiência, Gestão e Contratos no Sistema Agroindustrial, 2005. Disponível em: <http://www.sober.org.br/palestra/2/604.pdf>, Acesso em: 26 ago. 2009.

ASSOCIAÇÃO BRASILEIRA DE CELULOSE E PAPEL - BRACELPA. Relatório Estatístico 2004/2005. São Paulo, 2005.

. Relatório Estatístico 2005/2006. São Paulo, 2006.

. Relatório Estatístico 2007/2008. Disponível em: <http://www.bracelpa.org.br/bra/estatisticas/pdf/anual/rel2007.pdf>. Acesso em: 25 mar. 2009.

BAIN, Joe S. Industrial Organization. New York: John Wiley \& Sons, Inc, 1959.

BANCO NACIONAL DE DESENVOLVIMENTO ECONÔMICO E SOCIAL - BNDES. O Setor de Papel e Celulose no Brasil e no Mundo. Disponível em: «http://www.bndes.gov.br/conhecimento/relato/rel52b.pdf». Acesso em: 28 mar. 2009.

BARNEY, Jay B.; HESTERLY, William. Economia das Organizações: Entendendo a Relação entre as Organizações e a Análise Econômica. In: CALDAS, Miguel; FACHIN, Roberto; FISCHER, Tânia. Handbook de Estudos Organizacionais - Ação e Análise Organizacionais. v. 3. São Paulo: Atlas, 2004. p. 131-179.

BRAGA, R. Análise avançada do capital de giro. Caderno de Estudos, São Paulo, n. 3, p. 134, set. 1991. Disponível em: <http://www.eac.fea.usp.br/cadernos/ completos/cad03/analise.pdf>. Acesso em: 30 jun. 2008.

CABRAL, Luís M. B. Introduction to Industrial Organization. Massachusetts: MIT Press, 2000.

CARLTON, Dennis W; PERLOFF, Jeffrey M. Modern Industrial Organization. 2 ed. New York: Harper Collins, 1994.

COOPER, Donald R; SCHINDLER, Pamela S. Métodos de Pesquisa em Administração. 7 ed. Porto Alegre: Bookman, 2003.

DONSIMONI, Marie-Paule; GEROSKI, Paul; JACQUEMIN, Alexis. Concentration Indices and Market Power: Two Views. The Journal of Industrial Economics. v. 32, n. 4, p. 419 - 434, Jun. 1984.

FLEURIET, Michel; KEHDY, Ricardo; BLANC, Georges. O Modelo Fleuriet - A dinâmica financeira das empresas brasileiras. 4 ed. Rio de Janeiro: Elsevier, 2003.

FREITAS, Maria Ester de. Contexto Social e Imaginário Organizacional Moderno. RAE Revista de Administração de Empresas. São Paulo, v. 40, n. 2, p. 6 - 15, Abr./Jun. 2000. 
GEROSKI, Paul. Interpreting a Correlation between Market Structure and Performance. The Journal of Industrial Economics. v. 30, n. 3, p. 319 - 326, Mar. 1982.

JORGE, Maurício Mendonça. Nota técnica setorial: Competitividade da indústria de celulose. In: Estudo da competitividade da indústria brasileira. Campinas: FINEP/ MCT/FECAMP/UNICAMP-IE/ UFRJ-IEI, 1993.

KON, Anita. Economia Industrial. São Paulo: Nobel, 1999.

LEITE, André Luis da Silva. Concentração e desempenho competitivo no complexo industrial de papel e celulose 1987-1996. 1998. 98f. Dissertação (Mestrado em Engenharia de Produção). Universidade Federal de Santa Catarina. Florianópolis, 1998.

MACHADO, Esmael Almeida; GARCIAS, Paulo Mello; ALMEIDA, Lauro Brito; MORCH, Rafael Borges; BACARJI, Alencar Garcia. Endogenia entre as varáveis de Estrutura-CondutaDesempenho: Estudo Empírico na Indústria de Lacticínios do Brasil (1997-2006). In: XI Semead - Empreendedorismo em organizações, 2008.

MASON, Edward S. Price and Production Policies of Large-Scale Enterprises. American Economic Review. v. 29, p. 61 - 74, Mar 1939.

MEDEIROS, Otávio Ribeiro de; RODRIGUES, Fernanda Fernandes. Questionando Empiricamente a Validade do Modelo Fleuriet. BASE - Revista de Administração e Contabilidade da Unisinos. v. 1, n. 2, p. 25 - 32, Set./Dez. 2004.

MELHORES e MAIORES. Anuário da Revista Exame, 2008.

MONTEBELLO, Adriana Estela S. Análise da evolução da indústria brasileira de celulose no período de 1980 a 2005. 2006. 114f. Dissertação (Mestrado em Economia Aplicada) Escola Superior de Agricultura “Luiz de Queiroz”, Universidade de São Paulo. Piracicaba

ROCHA, Frederico; BUENO, Sálua; PIRES, Luiza Nassif. Dinâmica da Concentração de Mercado na Indústria Brasileira, 1996 - 2003. In: ANPEC, XXXV, 2007. Anais Eletrônicos do XXXV Encontro Nacional de Economia da ANPEC. Disponível em: <http://www.anpec.org.br/encontro2007/artigos/A07A141.pdf>. Acesso em: 27/03/2009.

SATO, Sonia S. Análise econômico-financeira setorial: estudo da relação entre liquidez e rentabilidade sob a ótica do modelo dinâmico. 2009. 204f. Dissertação (Mestrado em Engenharia de Produção) - Escola de Engenharia de São Carlos - Universidade de São Paulo. São Carlos, 2007. Disponível em: <http://www.teses.usp.br/teses/disponiveis/18/18140/tde-05032008-

110440/publico/DissertacaoSoniaSanae. pdf>. Acesso em: 27 mar. 2009.

SCHERER, Frederic M; ROSS, David. Industrial market structure and economic performance. 3 ed. Boston: Houghton M. Company, 1990.

SCHMALENSEE, R. Inter-industry studies of structure and performance. In: SCMALENSEE, R. e WILLING, R. Handbook of Industrial Organization. North Holland, Amsterdam, 1989.

SILVEIRA, Moisés Prates; ESPEJO, Robert Armando; PERUCELO, Marcos Roberto. As Análises Econômico-Financeira Tradicional e Dinâmica e o Desempenho Percebido pelo Mercado de Ações: um estudo de empresas do setor têxtil e vestuário do Brasil no período de 1998 a 2007. In: XII Congresso de Contabilidade e Auditoria, Anais do XII Congresso de Contabilidade e Auditoria. Aveiro, 2008.

SIMÕES, Pablo Nostre. Uma Análise sobre a Estrutura, Conduta e Desempenho do Setor de Supermercados do Brasil. São Paulo, 2006. 106f. Dissertação (Mestrado em Economia) Pontifícia Universidade Católica de São Paulo. 
SOARES, Sebastião José $M$. Nota técnica setorial: Competitividade da indústria de papel. In: Estudo da competitividade da indústria brasileira. Campinas: FINEP/ MCT/FECAMP/UNICAMP-IE/ UFRJ-IEI, 1993.

TIROLE, Jean. The theory of industrial organization. Massachusetts: MIT Press, 1988.

\section{ENDEREÇO DOS AUTORES}

Faculdade Anchieta de Ensino Superior do Paraná Rua Pedro Gusso, 4150 - Cidade Industrial Curitiba, PR - Brasil 81315-000

Departamento de Ciências Econômicas Universidade Federal do Paraná.

Av. Prefeito Lothário Meissner, 340 - Jardim Botânico Curitiba, PR - Brasil 80210-270 